Tohoku J. exp. Med., 1987, 153, 123-132

\title{
The Significance of Activation of Reticuloendothelial Function on Hepatectomy
}

\author{
Kunitoshi Nakagawa, Kiyoaki Ouchi, Shuji \\ Matsubara, Luis Hashimoto and Yoshiaki Yajima* \\ The First Department of Surgery, and *the Third \\ Department of Internal Medicine, Tohoku University School \\ of Medicine, Sendai 980
}

\begin{abstract}
Nakagawa, K., Ouchi, K., Matsubara, S., Hashimoto, L. and Yajima, Y. The Significance of Activation of Reticuloendothelial Function on Hepatectomy. Tohoku J. exp. Med., 1987, 153 (2), 123-132 — The prognosis of patients after massive hepatectomy is poor in certain cases whose hepatic reserve, including reticuloendothelial function, is deteriorated. We administered OK-432 before $70 \%$ hepatectomy on rats to activate the reticuloendothelial function and studied its effect on postoperative course. The elevations in plasma endotoxin, GOT and GTP were attenuated, and the deterioration of the complement activity after hepatectomy was greatly improved by OK- 432 treatment. The RNA content in the liver was significantly increased by OK-432 administration. These findings suggest that activation of the reticuloendothelial function at the time of massive hepatectomy enhances endotoxin clearance from blood and thereby contributes in lessening the magnitude of hepatic injury, maintaining the serum complement, and improving liver protein synthesis. — massive hepatectomy; reticuloendothelial function; endotoxemia; postoperative liver injury
\end{abstract}

Massive hepatectomy sometimes induces postoperative multiple organ failure (MOF) such as liver failure, renal failure, respiratory failure, disseminated intravascular coagulation (DIC) and gastrointestinal bleeding. It has been pointed out that deterioration in the clearance of toxic substances, including endotoxin, due to a decreased reticuloendothelial function, is involved in the pathogenesis of these surgical complications. We, therefore, performed $70 \%$ hepatectomy in rats which had been treated with OK-432 (Chugai Pharmaceutical Co., Tokyo) to activate the reticuloendothelial function and evaluated the significance of the activation of this function from various aspects of blood endotoxin level, total hemolytic complement $\left(\mathrm{CH}_{50}\right)$ and liver function tests, energy metabolism and regeneration of the liver.

\section{Materials and Methods}

Male Spraque-Dawley rats weighing 200 to $250 \mathrm{~g}$ were used in the present experiments.

Received March 31, 1987 ; accepted for publication August 10, 1987. 
The animals were divided into two groups: the OK-432 group, which received intraperitoneal injection of $\mathrm{OK}-432$ at a dose of $25 \mathrm{KE}$ dissolved in $2 \mathrm{ml}$ of saline 48 and $24 \mathrm{hr}$ prior to hepatectomy, to activate the reticuloendothelial function and the control group without injection. Under ether anesthesia, the rats underwent $70 \%$ hepatectomy according to the standard method described by Higgins and Anderson (1931) and various examinations were performed.

\section{Determination of the reticuloendothelial function}

Twenty four hr after laparotomy or hepatectomy, the reticuloendothelial function was determined according to the method of Ota (Ota 1969). ${ }^{59} \mathrm{Fe}$-chondroitin sulfate iron colloidal particle (specific radioactivity: $8.4 \mu \mathrm{ci} / \mathrm{Fe} 4 \mathrm{mg} /$ chondroitin sulfate $20 \mathrm{mg} / \mathrm{ml}$ ) was given by rapid intravenous injection at a volume of $0.5 \mathrm{ml} / \mathrm{kg}$ body weight. Blood samples $(0.1 \mathrm{ml})$ were drawn via the femoral artery prior to and 5 and $20 \mathrm{~min}$ after injection, and the radioactivity contents were counted in a scintillation counter. The phagocytic index $\mathrm{K}$ was calculated according to the method of Halpern (Halpern et al. 1953) using the following equation.

$$
\mathrm{K}=\frac{\log \mathrm{C}_{1}-\log \mathrm{C}_{2}}{\mathrm{~T}_{2}-\mathrm{T}_{1}}
$$

$\mathrm{C}_{1}$ : radioactivity (cpm) per $0.1 \mathrm{ml}$ of blood at $\mathrm{T}_{1}$

$\mathrm{C}_{2}$ : radioactivity $(\mathrm{cpm})$ per $0.1 \mathrm{ml}$ of blood at $\mathrm{T}_{2}$

Twenty min following the injection of ${ }^{59} \mathrm{Fe}$-chondroitin sulfate iron colloidal particle, the body was perfused with viviperfusion (Copp and Greenberg 1946) and the homogenates of the liver, spleen and lung were prepared. After radioactivity measurement, ${ }^{59} \mathrm{Fe}$ uptake by each organ was calculated.

\section{Determination of blood endotoxin}

Prior to and 12, 24, 36 and $48 \mathrm{hr}$ after hepatectomy, blood samples for endotoxin measurement were aseptically taken with heparinized syringes. The blood samples were centrifuged at $150 \times \mathrm{g}$ for $10 \mathrm{~min}$, and the supernatants (platelet rich plasma) were stored at $-80^{\circ} \mathrm{C}$. Endotoxin was assayed using the Limulus Colorimetric Test (Toxicolor Test, Seikagakukogyo, Tokyo) with the perchloric acid pretreatment (Iwanaga et al. 1978).

\section{Liver function tests and titration of serum complement}

As described above, blood samples were periodically drawn from the rats and were used for liver function tests and determination of hemolytic activity of complement $\left(\mathrm{CH}_{50}\right)$. GOT and GPT were determined by the Reitman-Frankel-Momose modification method, and LDH by the PMS-nitro TB modification method. Hemolytic activity of complement was measured according to the method of Mayer (Mayer 1961).

\section{Determination of the mitochondrial respiratory function}

As described above, the rat livers were excised, and mitochondrial fractions were obtained according to the method of Hogeboom and Schneider (1948). The mitochondrial respiratory function was examined by an oxygen consumption meter (Model 5/6, Oxygraph, Gilson, Bal, France) using succinate as the substrate. From the oxygen consumption curve obtained, oxygen consumption in state 3 , adenosine diphosphate/oxygen ratio $(\mathrm{P} / \mathrm{O})$ and, based on these, the rate of adenosine triphosphate (ATP) synthesis were calculated (Koyama et al. 1982).

\section{Determination of $R N A$ and DNA synthesis and content}

At $11,23,35$ and $47 \mathrm{hr}$ after hepatectomy, rats were given an intraperitoneal administration of ${ }^{3} \mathrm{H}$-Orotic acid $(20 \mu \mathrm{ci} / 100 \mathrm{~g})$. One hr later, the liver was excised, and RNA and DNA were extracted according to the Schmidt-Thannhauser-Schneider method (Schneider 
1946). Radio-activities in RNA and DNA fractions were determined, and the rates of RNA and DNA synthesis were calculated using the values of specific radioactivities. The RNA and DNA contents were quantified by the orcinol and diphenylamine method, respectively.

All data were expressed as means \pm S.D. and the statistic significance of difference was evaluated according to Student's $t$-test. Differences were judged to be significant when $p$ values were less than 0.05 .

\section{Results}

\section{Reticuloendothelial function}

In the control group, the phagocytic index $\mathrm{K}$ decreased to about $1 / 2$ after $70 \%$ hepatectomy (Fig. 1). In the OK-432 group, however, the function of the reticuloendothelial system was markedly activated. As compared with the values in the control group, the phagocytic index $\mathrm{K}$ in this group was 1.6-fold higher after laparotomy and 1.2-fold higher $24 \mathrm{hr}$ after $70 \%$ hepatectomy.

The values of ${ }^{59} \mathrm{Fe}$ uptake are shown in Fig. 2 ; in the control group, ${ }^{59} \mathrm{Fe}$ uptake to the liver was $32.2 \pm 5.3 \%$ after laparotomy, while those of the spleen and lung were as low as $1.6 \pm 0.1 \%$ and $0.2 \pm 0.1 \%$, respectively. After $70 \%$ hepatectomy, ${ }^{59} \mathrm{Fe}$ uptake to the liver was markedly reduced to $10.0 \pm 1.7 \%$, while ${ }^{59} \mathrm{Fe}$ uptakes to the spleen and lung were increased. Particulary, uptake to the

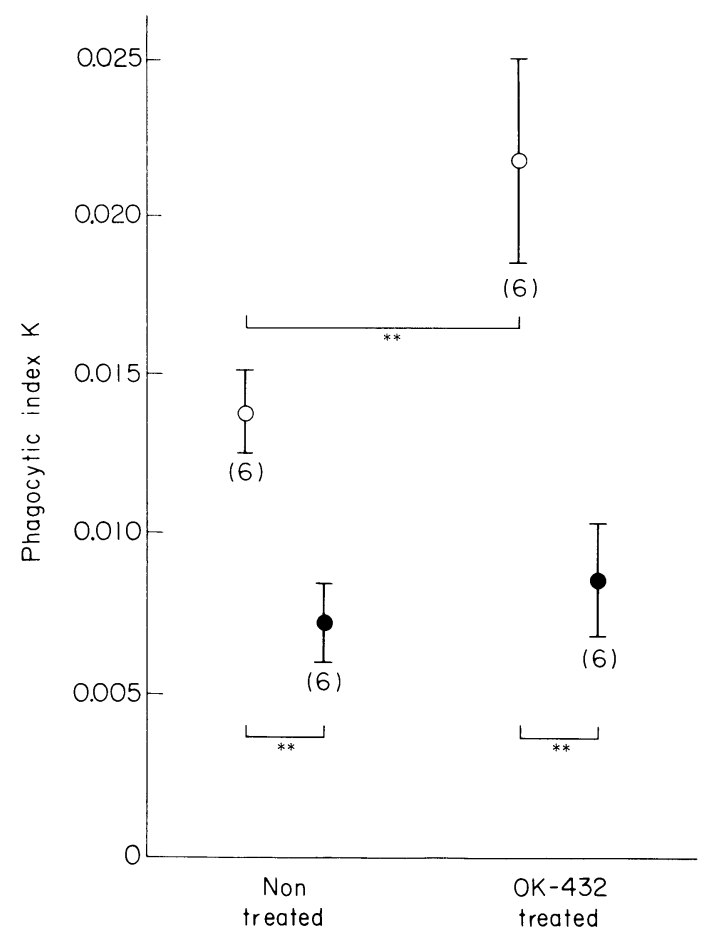

Fig. 1. Phagocytic index $\mathrm{K}$ after laparotomy and $70 \%$ hepatectomy. Data points are means \pm S.D. Experimental numbers are in parentheses. 0 , laporotomy group; $\bullet$, hepatectomy group. ${ }^{* *} p<0.01$. 

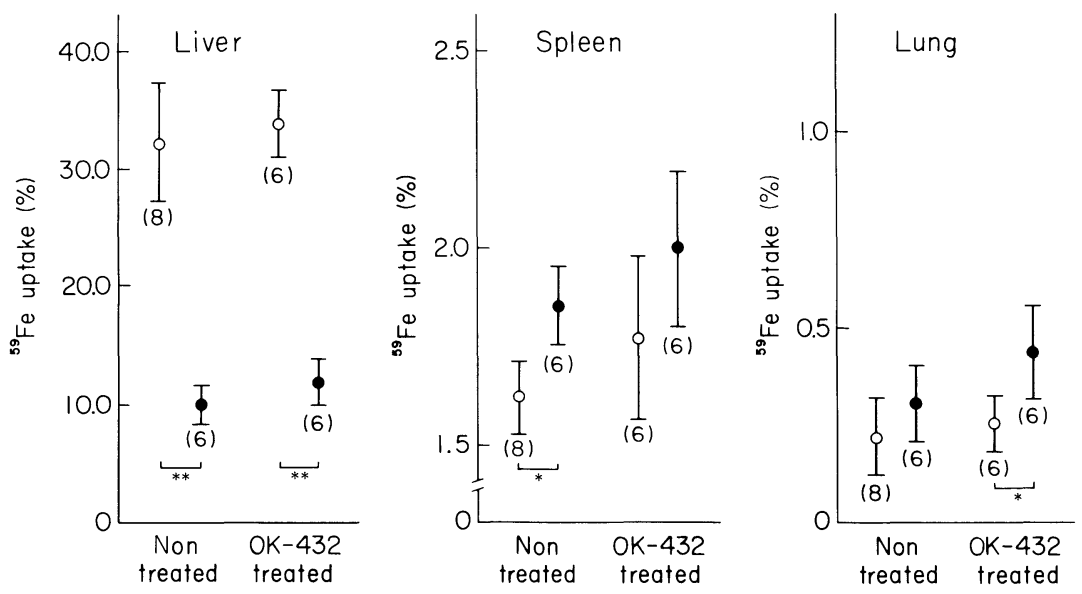

Fig. 2. ${ }^{59} \mathrm{Fe}$ uptake in liver, spleen and lung after laparotomy and $70 \%$ hepatectomy. Data points are means \pm s.D. Experimental numbers are in parentheses. $\bigcirc$, laparotomy group; $\bullet$, hepatectomy group. ${ }^{*} p<0.05$; ${ }^{* *} p<0.01$.

spleen was significantly increased. Meanwhile, in the OK-432 group, ${ }^{59} \mathrm{Fe}$ uptakes to the liver, spleen, and lung tended to be higher than those in the control group, and a similar tendency was also seen after hepatectomy.

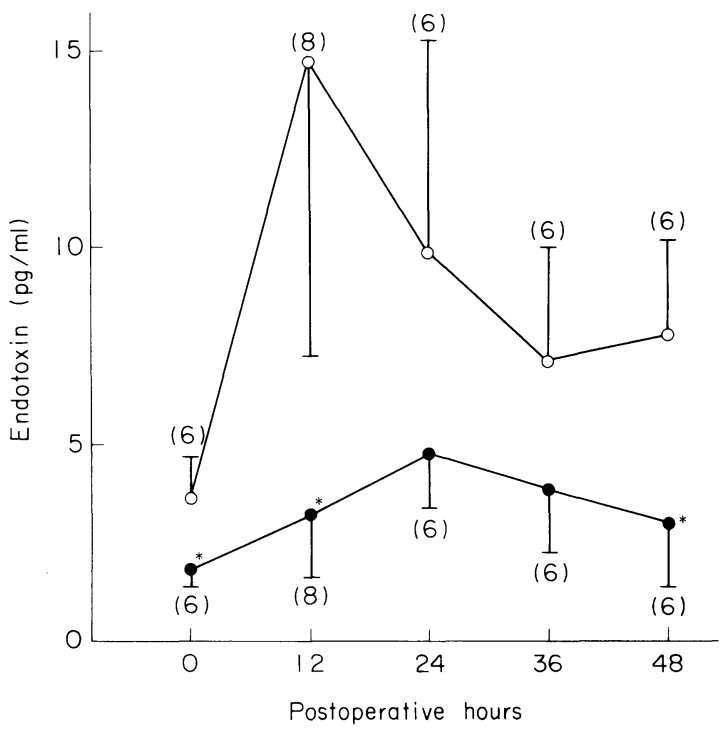

Fig. 3. Changes of endotoxin levels after $70 \%$ hepatectomy. Data points are means \pm s.D. Experimental numbers are in parentheses. O, control (OK432 -untreated) group; •, OK-432 group. ${ }^{*} p<0.05$ against corresponding value in the control group. 


\section{Blood endotoxin level}

Immediately before hepatectomy, the blood endotoxin level in the control group was $3.6 \pm 1.1 \mathrm{pg} / \mathrm{ml}$, which was significantly higher than that of $1.9 \pm 0.6 \mathrm{pg} /$ $\mathrm{ml}$ in the OK-432 group (Fig. 3). In the control group, the blood endotoxin level was markedly increased after hepatectomy, reaching the maximal value of $14.7 \pm$ $7.5 \mathrm{pg} / \mathrm{ml} 12 \mathrm{hr}$ after hepatectomy, then reached the value of $7.7 \pm 2.4 \mathrm{pg} / \mathrm{ml}$ even $48 \mathrm{hr}$ after hepatectomy, which was significantly higher than that of $2.9 \pm 1.5 \mathrm{pg} /$ $\mathrm{ml}$ in the OK-432 group. The maximal value in the OK-432 group, which was reached $24 \mathrm{hr}$ postoperatively, was only $4.7 \pm 1.3 \mathrm{pg} / \mathrm{ml}$.

\section{Liver function tests and serum complement}

In the control group, GOT, GPT and LDH levels were markedly elevated after hepatectomy, showing the maximal values of $633 \pm 75$ international unit (IU)/liter, $833 \pm 225 \mathrm{IU} /$ liter, and $2501 \pm 375 \mathrm{IU} /$ liter, respectively, at $12 \mathrm{hr}$ after hepatectomy (Fig. 4). Although a similar tendency was also noted in the OK-432 group, the magnitude of increases in GOT and GPT was significantly lower than the control group.

As shown in Fig. 5, the hemolytic activity of complement $\left(\mathrm{CH}_{50}\right)$ decreased after hepatectomy, but the administration of OK-432 improved the deterioration of complement activity. Twelve hr after hepatectomy, in particular, the hemolytic activity of complement in the OK-432 group was $61.5 \pm 15.2$ unit $/ \mathrm{ml}$, which was significantly higher than $36.5 \pm 9.4 \mathrm{unit} / \mathrm{ml}$ in the control group.
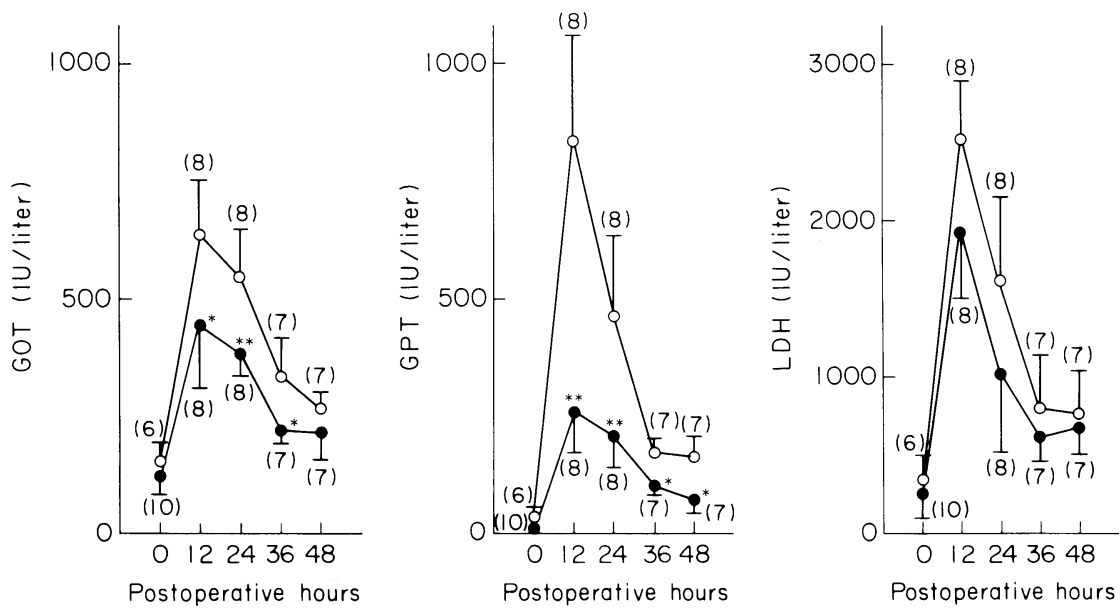

Fig. 4. Changes of GOT, GPT and LDH after 70\% hepatectomy. Data points are means \pm s.D. Experimental numbers are in parentheses. $c$, control group ; •, OK-432 group. ${ }^{*} p<0.05,{ }^{* *} \mathrm{p}<0.01$ against corresponding values in the control group. 


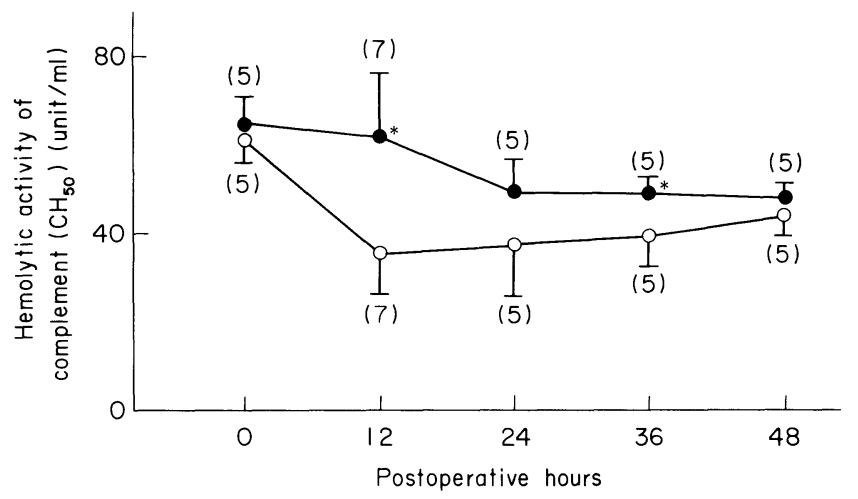

Fig. 5. Changes of the hemolytic activity of complement $\left(\mathrm{CH}_{50}\right)$ after $70 \%$ hepatectomy. Data points are means \pm s.D. Experimental numbers are in parentheses. $\bigcirc$, control group; $\bullet, \mathrm{OK}-432$ group. ${ }^{*} p<0.05$ against corresponding values in the control group.

\section{Mitochondrial respiratory function}

After hepatectomy, ATP synthesis increased, reaching the maximal value of $186.3 \pm 36.3 \mathrm{nmole} / \mathrm{min} / \mathrm{mg} 24 \mathrm{hr}$ after hepatectomy (Fig. 6). The administration of OK-432 tended to enhance the increase in ATP synthesis, but no significant difference was noted between the OK-432 and the control groups.

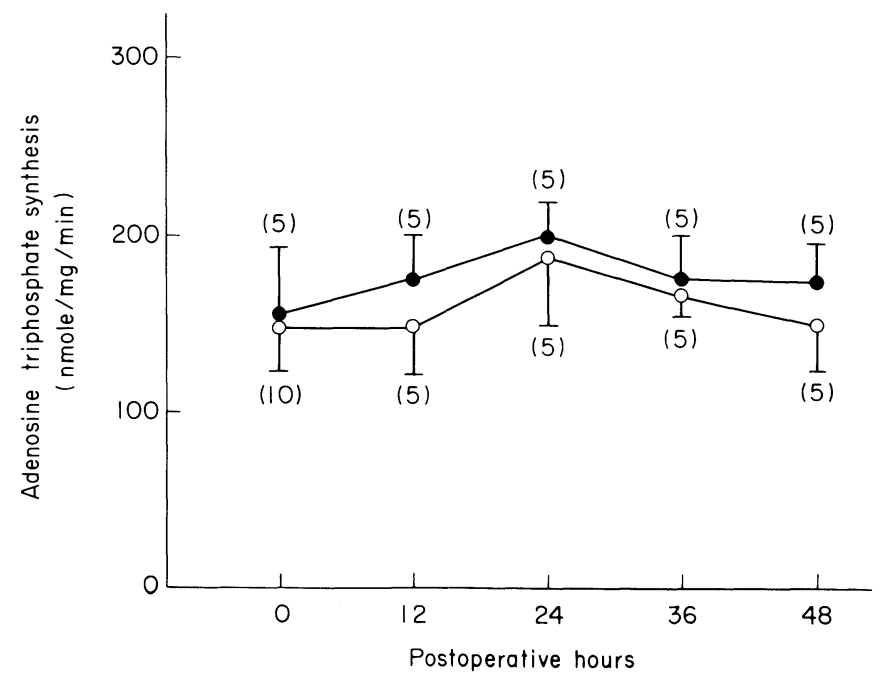

Fig. 6. Changes of ATP synthesis after 70\% hepatectomy. Data points are means \pm S.D. Experimental numbers are in parentheses. $\bigcirc$, control group; -, OK-432 group. 

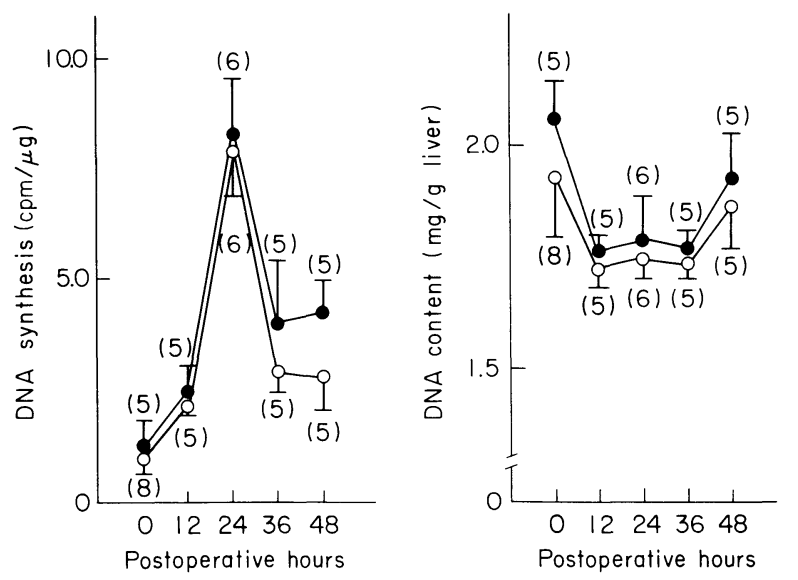

Fig. 7. Changes of DNA synthesis and content after $70 \%$ hepatectomy. Data points are means \pm S.D. Experimental numbers are in parentheses. O, control group ; •, OK-432 group.

\section{$R N A$ and DNA synthesis and content}

DNA synthesis in the liver reached the maximal value of $7.9 \pm 1.2 \mathrm{cpm} / \mu \mathrm{g} 24$ hr after hepatectomy and decreased steeply thereafter (Fig. 7). The DNA content which decreased after hepatectomy returned to the initial level $48 \mathrm{hr}$ later. Neither DNA synthesis nor content in the OK-432 group demonstrated significant difference from the control group. In the control group, RNA synthesis increased markedly up to $72.5 \pm 10.9 \mathrm{cpm} / \mu \mathrm{g} 12 \mathrm{hr}$ after hepatectomy and decreased gradually thereafter (Fig. 8). With the administration of OK-432, RNA synthesis was
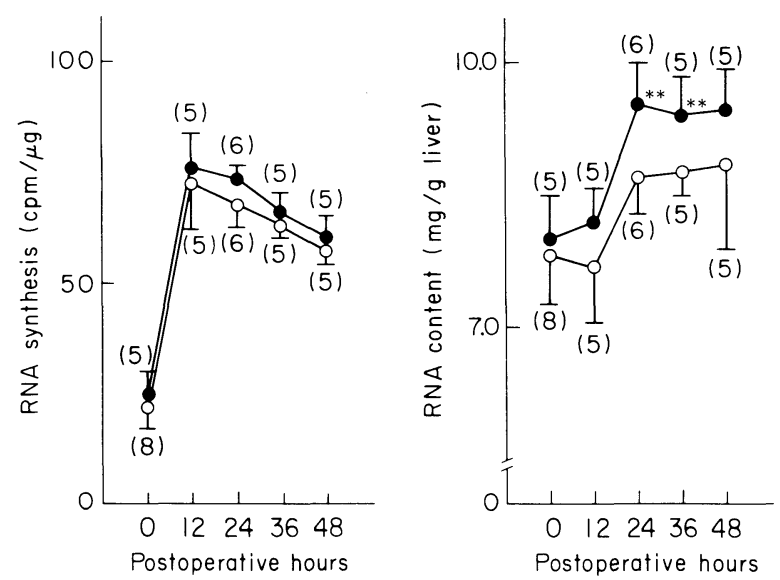

Fig. 8. Changes of RNA synthesis and content after $70 \%$ hepatectomy. Data points are means \pm S.D. Experimental numbers are in parentheses. $\odot$, control group ; •, OK-432 group. ${ }^{* *} p<0.01$ against corresponding value in the control group. 
little increased. On the other hand, the RNA content which increased gradually after hepatectomy were $9.5 \pm 0.5 \mathrm{mg} / \mathrm{g}$ liver and $9.4 \pm 0.4 \mathrm{mg} / \mathrm{g}$ liver, respectively, at the 24th and 36th postoperative $\mathrm{hr}$ in the OK-432 group. Those were significantly higher than the control group having $8.6 \pm 0.3 \mathrm{mg} / \mathrm{g}$ liver $(24 \mathrm{hr})$ and $8.7 \pm 0.2 \mathrm{mg} / \mathrm{g}$ liver $(36 \mathrm{hr})$, respectively.

\section{Discussion}

Hepatectomy is sometimes associated with surgical complications. Particularly, in cases with liver cirrhosis, this tendency is quite prominent, and the postoperative course is frequenly eventful (Iwatsuki et al. 1983). It has been pointed out that the pathogenesis of MOF associated with hepatectomy involves deteriorated phagocytic capacity of the reticuloendothelial system throughout the body, particularly for Kupffer cells. The decreased clearance of toxic substances in blood, such as endotoxin, bacteria, antigen, and many toxic metabolites, due to the depressed function of the reticuloendothelial system, contributes to the onset of MOF. Recently, to remove these substances in blood, plasma exchange has been performed in an increasing number of cases. However, this requires a large volume of plasma, and, moreover, its practical effect is limited. Therefore, we decided to study the activation of the reticuloendothelial function to possibly improve the clearance of those toxic substances.

OK-432 was chosen as the activator of the reticuloendothelial function because of its easy availability and safety in clinical practice. This agent is a biological drug prepared by co-culture of Streptococcus hemolytics Su strain with penicillin $\mathrm{G}$ in a given condition and liophilization and is now widely used in the treatment of cancer as a immunoactivator. OK-432 enhances not only the immunological competence but also the reticuloendothelial function, and we have already confirmed these actions both experminetally and clinically (Nakagawa et al. 1985). The present experiment also confirmed that OK-432 tended to increase ${ }^{59} \mathrm{Fe}$ uptake to the liver, spleen, and lung as well as significantly increased phagocytic index $\mathrm{K}$.

Endogenous endotoxin derives from the intestinal flora and is cleared primarily by Kupffer cells in the liver. However, in cases undergone massive hepatectomy, where the reticuloendothelial function is markedly deteriorated, spillover of endotoxin into the systemic circulation might have a chance to impair various organs, finally reaching to MOF (Yajima et al. 1985; Nakagawa et al. 1986). In the present experiment, the blood endotoxin level after hepatectomy was markedly increased in the control group, however, in the group where the reticuloendothelial function was activated by OK-432, the rise of the blood endotoxin was slight. This finding suggests the possibility that, in cases undergone massive hepatectomy, the activation of the reticuloendothelial function may enhance the clearance of toxic substances, such as endotoxin. It might be benefical to prevent the development of surgical complications. 
Serum enzymes such as GOT and LDH are thought to appear in blood during liver injury, such as hepatolysis or increased hepatocellular permeability (Sekas and Cook 1979). OK-432 significantly suppressed the increases of GOT and GPT after hepatectomy by two possible mechanisms, the first; increased clearance of toxic substances such as endotoxin with the consequent prevention of the onset of liver injury, and the other; increased clearance of the serum enzymes by the activated reticuloendothelial function.

Since the liver is the major site of synthesis of complement components, a massive hapatectomy resulted in a marked drop in the hemolytic activity of complement $\left(\mathrm{CH}_{50}\right)$. It is also known that reduced serum complement levels are due to immunologic activation of the complement components by immune complexes and consequent increases in complement consumption (Wyke et al. 1980). In the present experiment, the lowered complement levels after hepatectomy was significantly improved by the administration of OK-432. It is suggested that OK-432 has the inhibitory action on the activation or consumption of complement components.

After hepatectomy, the residual liver requires a large amount of energy for the synthesis of nucleic acid and proteins necessary for liver regeneration, and the majority of their energy is supplied by ATP, which is produced in the hepatic mitochondria (Ozawa et al. 1982). For an adequate energy supply, increased ATP synthesis by the hepatic mitochondria is vital, and this was confirmed in our study. Furthermore, the increased energy metabolism in the regenerating liver after hepatectomy is followed by a increased synthesis of nucleic acids (Hecht and Potter 1956). In the present experiment, more prominent increases in the RNA content was achieved in the OK-432 group.

All these results suggest that the OK-432-induced activation of the reticuloendothelial function may be beneficial for the prevention of the development of postoperative complications as well as for the suppression of the liver damage induced by hepatectomy.

\section{References}

1) Copp, D.H. \& Greenberg, D.M. (1946) A tracer study of iron metabolism with radioactive iron. J. biol. Chem., 164, 389-401.

2) Halpern, B.W., Benacerraf, B. \& Biozzi, G. (1953) Quantitative study of the granulopoietic activity of the reticuloendothelial system. Brit. J. exp. Path., 34, $426-440$.

3) Hecht, L.I. \& Potter, V.R. (1956) Nucleic acid metabolism in regenerating rat liver. Cancer Res., 16, 988-993.

4) Higgins, G.M. \& Anderson, R.M. (1931) Experimental pathology of the liver. Arch. Path., 12, 186-202.

5) Hogeboom, G.H. \& Schneider, W.C. (1948) Isolation of intact mitochondria from rat liver. J. biol. Chem., 172, 619-635.

6) Iwanaga, S., Morita, T., Harada, T., Nakamura, S., Niwa, M., Takada, K., Kimura, T. \& Sakakibara, S. (1978) Chromogenic substrates for horseshoe crab clotting enzyme. 
Its application for the assay of bacterial endotoxins. Haemostasis, 7, 183-188.

7) Iwatsuki, S., Byers, W., Shaw, J.R., Thomas, E. \& Strarzl, T.E. (1983) Experience with 150 liver resections. Ann. Surg., 197, 247-253.

8) Koyama, K., Otowa, T., Yamauchi, H., Okabe, K. \& Sato, T. (1982) Significance of prednisolone administration for hepatic mitochondrial function of the rat with biliary obstruction. Tohoku J. exp. Med., 138, 17-25.

9) Mayer, M.M. (1961) Complement and complement fixation. In: Experimental Immunochemistry, edited by E.A. Kabat \& M.M. Mayer, Charles C Thomas, Springfield-Illinosis, pp. 133-140.

10) Nakagawa, K., Koyama, K., Asanuma, Y. \& Sato, T. (1985) The significance of the activation of the reticuloendothelial system on the resection of the cirrhotic liver. Acta hepat. jap., 26, 445-452. (in Japanese with English abstract)

11) Nakagawa, K., Matsubara, S., Ouchi, K., Owada, Y. \& Yajima, Y. (1986) Endotoxemia after abdominal surgery. Tohoku J. exp. Med., 150, 273-280.

12) Ota, T. (1969) Studies on the reticuloendothelial function test using ironchondroitinsulfate compound. Med. J. Osaka Univ. (Jap. Ed.), 21, 147-170. (Japanese)

13) Ozawa, K., Fujimoto, T. \& Nakatani, T. (1982) Changes in hepatic energy charge, blood ketone body ratio, and indocyanine green clearance in relation to DNA synthesis after hepatectomy. Life Sci., 31, 647-655.

14) Schneider, W.C. (1946) Phosphorus compounds in animal tissues. J. biol. Chem., 164, 747-751.

15) Sekas, G. \& Cook, R.T. (1979) The evaluation of liver function after partial hepatectomy in the rats. Brit. J. exp. Path., 60, 447-452.

16) Wyke, R.I., Rajkovic, I.A. \& Williams, R. (1980) Defective opsonisation and complement deficiency in serum from patients with fulminant hepatic failure. Gut, 21, 643649 .

17) Yajima, Y., Fukuda, I., Otsuki, M., Suzuki, H., Ota, S., Ishii, M., Mori, K. \& Goto, Y. (1985) Endotoxemia in liver diseases: Detection by a quantitative assay using chromogenic substrate with perchloric acid pretreatment. Tohoku J.exp. Med., 147, 411-419. 